\title{
Risk of Bleeding Complications after Preoperative Antiplatelet Withdrawal versus Continuing Antiplatelet Drugs during Transurethral Resection of the Prostate and Prostate Puncture Biopsy: A Systematic Review and Meta-Analysis
}

\author{
Jiawu Wang ${ }^{\mathrm{a}}$ Chengyao Zhang $^{\mathrm{b}}$ Guangzhong Tan ${ }^{\mathrm{a}}$ Wenkai Chen ${ }^{\mathrm{a}}$ Bo Yang ${ }^{\mathrm{a}}$ \\ Dan $\operatorname{Tan}^{\mathrm{a}}$

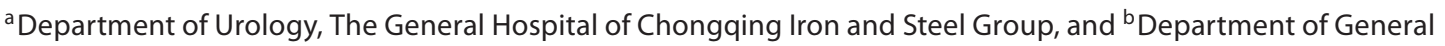 \\ Surgery, The First Affiliated Hospital of Chongqing Medical University, Chongqing, China
}

\section{Key Words}

Antiplatelet drugs - Bleeding - Transurethral resection of the prostate $\cdot$ Prostate puncture biopsy $\cdot$ Meta-analysis

\begin{abstract}
Objective: To systematically evaluate the risk of antiplatelet drugs (APs) on bleeding complications in urological surgery. Methods: Studies were sought and included in this review if they were clinical controlled trials and involved transurethral resection of the prostate (TURP) and prostate puncture biopsy (PPB), which compared preoperative AP withdrawal (control group) with continuing APs (experimental group) and revealed bleeding complications as outcomes. A literature search was conducted of the electronic databases PubMed, Ovid, ScienceDirect and Embase for studies published between 1990 and 2012. Two reviewers independently screened the studies for eligibility, evaluated the quality and extracted the data from the eligible studies, with confirmation by cross-checking. There was evidence of publication bias based on Egger's test and funnel plot. Data were processed using Cochrane Review Manager 5.0 software. Results: Nine studies involving 3,145 cases met the inclusion criteria and were included in the meta-analysis. The base-
\end{abstract}

\section{KARGER}

Fax +4161306 1234

E-Mail karger@karger.ch

www.karger.com (c) 2012 S. Karger AG, Basel

0042-1138/12/0894-0433\$38.00/0

Accessible online at:

www.karger.com/uin lines of patients' characteristics were comparable in all studies. The meta-analysis results showed that no differences were found in risk of bleeding after (1) TURP (OR $1.26,95 \% \mathrm{Cl}$ $0.80-2.00, \mathrm{p}=0.32$ ) or (2) PPB (OR $0.89,95 \% \mathrm{Cl} 0.45-1.76, \mathrm{p}=$ 0.73). Conclusion: Preoperative APs do not raise the risk of surgical bleeding complications in prostatectomy and PPB. Because of few studies and small samples, more high-quality trials with larger samples and longer follow-ups are proposed.

Copyright @ 2012 S. Karger AG, Basel

\section{Introduction}

Currently, patients with angiocardiopathy, such as chronic auricular fibrillation, postoperative heart valve prosthesis, and thrombus tendency, need to ingest lowdose antiplatelet drugs (APs) such as aspirin (acetylsalicylic acid) in the long term to prevent thrombosis. No defined clinical conclusion exists whether patients need to discontinue APs before undergoing transurethral resection of the prostate (TURP) and prostate puncture biopsy (PPB). Burger et al. [1] considered the risk of cardiovascular complications resulting from stopping APs; 
nonetheless, we should still stop APs perioperatively because even low-dose APs may lead to an increased risk of bleeding and associated complications. Kretschmer [2] reported that continuing APs preoperation is not a significant contraindication of surgical operation.

In our study, a large database of patients who were eligible for clinical trials was collected to assess bleeding complications of preoperative AP withdrawal and compared with continuing APs during TURP and PPB in order to obtain definitive conclusions for clinical practice.

\section{Materials and Methods}

\section{Inclusion and Exclusion Criteria}

Inclusion criteria for the studies retrieved were as follows: (1) Clinical controlled trials, including retrospective and randomized studies, and published in English. (2) Patients took oral low-dose APs before TURP and prostate biopsy. There were no restrictions concerning race, age, gender and duration of disease. (3) In intervention studies, the experimental group of patients continued APs preoperation; in the control group patients discontinued APs. Duration of stopping APs was 5-10 days, and the other interventions were the same as those in the experimental group. (4) The main outcomes were bleeding complications, including postoperative hemorrhage, bleeding transfusion rate, hematuria, hemospermia and hemoglobin. Exclusion criteria were pregnant patients, hemophilia and other hemorrhagic diseases.

\section{Data Sources and Literature Search}

As required by the Cochrane Reviewers' Handbook, two investigators developed the search methods. A literature search of the electronic databases PubMed, Ovid, ScienceDirect and Embase was conducted for studies published between 1990 and 2012 . The search terms were: antiplatelet, bleeding, TURP, PPB, metaanalysis and clinical trial.

\section{Data Collection}

We screened the studies according to inclusion and exclusion criteria. Two reviewers independently extracted data and appraised both quality and content. Any differences were resolved by mutual agreement. We supplemented incomplete data by contacting the author(s) of the relevant study. The two reviewers extracted data on: baseline patient characteristics, intervention, outcome measures, statistical methods and results.

\section{Quality Assessment}

The randomized controlled trials quality was judged by the same two reviewers according to Cochrane Reviewers' Handbook 5.0 [3]. For non-randomized controlled trials, we used the 'quality assessment and score table of non-randomized controlled clinical trials' from the Chinese Journal of Evidence-Based Medicine [4], which assessed studies consisting of blinding of outcome, grouping method, description of the follow-up situation if the patients were lost to follow-up, exit from or breach of the treatment regimen, baseline of research, and confounding factors.

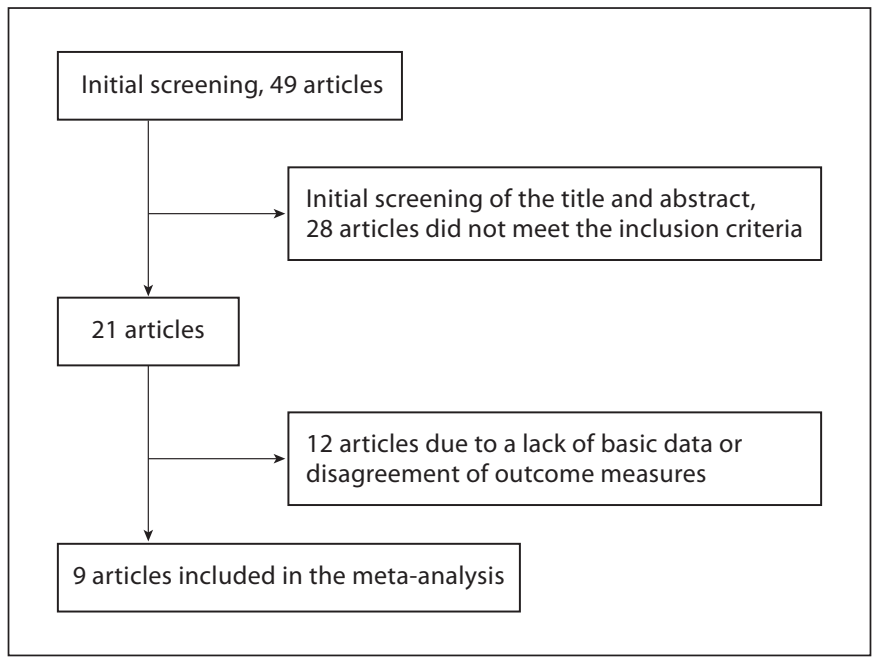

Fig. 1. Data selection process.

\section{Statistical Techniques}

All statistical analyses were done with Cochrane Review Manager 5.0 software. Effect size and statistical analysis methods were chosen according to the type of data and the purpose of the assessment. Heterogeneity among the studies was assessed using $\chi^{2}$ statistics $(\mathrm{p}=0.05)$, fixed-effect models were calculated for homogeneous data, and random-effects analysis was performed for heterogeneous data. For continuous variables, if results had the same units of measurement, we used weighted mean difference, otherwise we used standardized mean difference. For categorical variables, statistical analysis was carried out using risk ratios and 95\% CI. Potential publication bias was assessed with the Egger test and represented graphically by use of Begg's funnel plots of the natural log of the OR versus its standard error (SE). The meta-analysis results were expressed using forest graphs. A two-sided $\mathrm{p}$ value $<0.05$ was judged significant for all analyses.

\section{Results}

\section{Search Results and Study Selection}

We searched 49 references by computer and by hand. Following an initial screening of the title and abstract, 21 studies were thought to meet the inclusion criteria. Following a further screening of full texts, we excluded 12 articles due to a lack of basic data or disagreement of outcome measures. Finally, 9 studies published between 1990 and 2012 were included in the meta-analysis. The complete articles were retrieved. The flowchart of the data selection process is shown in figure 1 . Trial characteristics are shown in table 1. 
Table 1. Characteristics of studies included in the meta-analysis

\begin{tabular}{lllll}
\hline Study & Year & Operation type & Design method & Bleeding complications \\
\hline Ala-Opas [5] & 1996 & Prostatectomy & Retrospective controlled trial & Hematuria, hemoproctia, hemospermia \\
Wierød [6] & 1998 & Prostatectomy & Retrospective controlled trial & Blood transfusion rate \\
Giannarin [7] & 2007 & Prostatectomy & Randomized controlled trial & Hemorrhage \\
Herget [8] & 1999 & PPB & Retrospective controlled trial & Hematuria, hemoproctia, hemospermia \\
Kariotis [9] & 2010 & PPB & Retrospective controlled trial & Hematuria \\
Maan [10] & 2003 & PPB & Retrospective controlled trial & Hematuria, hemoproctia, hemospermia \\
Nielsen [11] & 2000 & Prostatectomy & Double-blind randomized controlled trial & Blood transfusion rate \\
Thurston [13] & 1993 & Prostatectomy & Retrospective controlled trial & Hb decreases $>2$ g/d or blood transfusion $>2$ units \\
Watson [14] & 1990 & Prostatectomy & Retrospective controlled trial & Blood transfusion rate \\
\hline
\end{tabular}

Table 2. Quality evaluation of studies included

\begin{tabular}{|c|c|c|c|c|c|}
\hline Study & Design method & $\begin{array}{l}\text { Allocation } \\
\text { concealment }\end{array}$ & Blinding & $\begin{array}{l}\text { Completeness } \\
\text { of follow-up }\end{array}$ & Base line \\
\hline Ala-Opas [5] & Retrospective controlled trial & N/A & $\mathrm{N} / \mathrm{A}$ & Reported & Consistency \\
\hline Wierød [6] & Retrospective controlled trial & $\mathrm{N} / \mathrm{A}$ & $\mathrm{N} / \mathrm{A}$ & Reported & Consistency \\
\hline Giannarin [7] & Randomized controlled trial & $\mathrm{N} / \mathrm{A}$ & N/A & Reported & Consistency \\
\hline Herget [8] & Retrospective controlled trial & $\mathrm{N} / \mathrm{A}$ & $\mathrm{N} / \mathrm{A}$ & Reported & Consistency \\
\hline Kariotis [9] & Retrospective controlled trial & $\mathrm{N} / \mathrm{A}$ & $\mathrm{N} / \mathrm{A}$ & Reported & Consistency \\
\hline Maan [10] & Retrospective controlled trial & N/A & $\mathrm{N} / \mathrm{A}$ & Reported & Consistency \\
\hline Nielsen[11] & Randomized controlled trial & N/A & Double-blind & Reported & Consistency \\
\hline Thurston [13] & Retrospective controlled trial & N/A & $\mathrm{N} / \mathrm{A}$ & Reported & Consistency \\
\hline Watson [14] & Retrospective controlled trial & N/A & N/A & Reported & Consistency \\
\hline
\end{tabular}

$\mathrm{N} / \mathrm{A}=$ Not available (insufficient information provided).

\section{Quality Assessment}

The trial by Nielsen et al. [11] is a double-blind, randomized controlled trial and scored 4 points by Jadad et al. [3]. Giannarin et al. [7] is a randomized controlled trial and scored 3 points. The other 8 trials were retrospective controlled trials. None of the trials had any description concerning loss to follow-up and exit from or breach of the treatment regimen. The patients' baseline characteristics were comparable and confounding factors controlled well in all the studies. Quality assessment is shown in table 2.

\section{Bleeding Complication Analysis \\ Effect of APs on Bleeding Complications during TURP}

Six trials reported a comparison of the effect of APs on bleeding complications during TURP. Among the trials included, the heterogeneity test revealed no significant departure from the $\chi^{2}$ test $\left(\mathrm{p}=0.08, \mathrm{I}^{2}=49 \%\right)$. Thus, OR calculations were performed according to the fixed-effects model. The results showed that there was no significant statistical difference of bleeding risk between con- tinuing and stopping the use of APs during TURP (OR $1.26,95 \%$ CI $0.80-2.00, \mathrm{p}=0.32$; fig. 2). That is to say, the difference of bleeding complications during TURP was not statistically significant.

Two of the 6 trials were randomized controlled trials, which were performed by subgroup meta-analysis. The heterogeneity test in the two trials revealed no significant departure from the $\chi^{2}$ test $\left(\mathrm{p}=0.17, \mathrm{I}^{2}=46 \%\right)$. Thus, OR calculations were performed according to the fixed-effects model. The results showed no significant statistical difference of bleeding risk between continuing and stopping APs before TURP (OR 0.79, 95\% CI 0.43-1.45, p = 0.45; fig. 3).

\section{Effect of APs on Bleeding Complications in PPB}

A comparison of the effect of APs on bleeding complications for PPB is shown in figure 4. Among the 9 trials, bleeding complications, including hematuria, hemoproctia and hemospermia, were selected as the outcome measure in three articles in PPB. All the three articles [8-10] reported respectively the incidence rate of hematuria, he- 


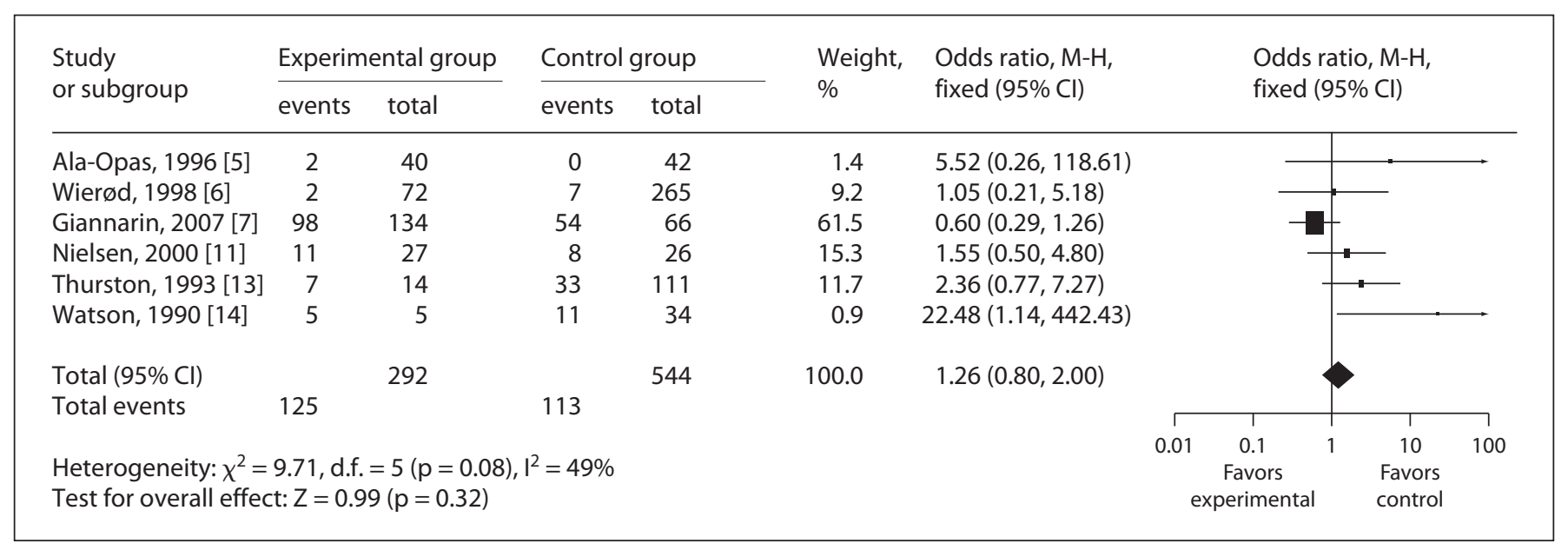

Fig. 2. Forest plot: bleeding complications after preoperative AP withdrawal versus continuing AP during TURP.

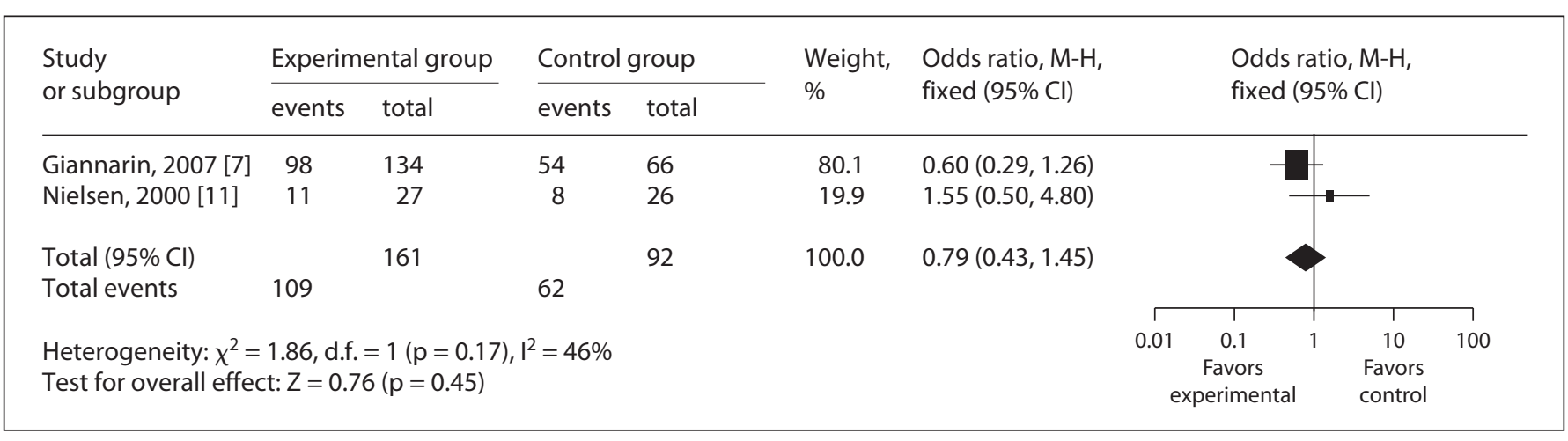

Fig. 3. Forest plot: bleeding complications after preoperative AP withdrawal versus continuing AP during TURP (randomized controlled trial).

\begin{tabular}{|c|c|c|c|c|c|c|c|c|c|c|}
\hline \multirow{3}{*}{$\begin{array}{l}\text { Study } \\
\text { or subgroup } \\
\text { Herget, } 1999 \text { [8] }\end{array}$} & \multicolumn{2}{|c|}{ Experimental group } & \multicolumn{2}{|c|}{ Control group } & \multirow{3}{*}{$\begin{array}{l}\text { Weight, } \\
\% \\
16.3\end{array}$} & \multirow{2}{*}{$\begin{array}{l}\text { Odds ratio } \mathrm{M}-\mathrm{H} \text {, } \\
\text { random }(95 \% \mathrm{Cl})\end{array}$} & \multirow{2}{*}{\multicolumn{4}{|c|}{$\begin{array}{l}\text { Odds ratio, } \mathrm{M}-\mathrm{H} \text {, } \\
\text { random }(95 \% \mathrm{Cl})\end{array}$}} \\
\hline & \multirow{2}{*}{$\frac{\text { events }}{2}$} & \multirow{2}{*}{$\frac{\text { total }}{54}$} & \multirow{2}{*}{$\frac{\text { events }}{44}$} & \multirow{2}{*}{$\frac{\text { total }}{1,712}$} & & & & & & \\
\hline & & & & & & $1.46(0.34,6.18)$ & & & - & \\
\hline Kariotis, 2010 [9] & 98 & 152 & 171 & 282 & 49.0 & $1.18(0.78,1.77)$ & & & & \\
\hline Maan, 2003 [10] & 22 & 38 & 105 & 141 & 34.8 & $0.47(0.22,1.00)$ & & $\rightarrow$ & & \\
\hline Total $(95 \% \mathrm{Cl})$ & & 244 & & 2,135 & 100.0 & $0.89(0.45,1.76)$ & & & & \\
\hline Total events & 122 & & 320 & & & & $\Gamma$ & t & $T$ & $\neg$ \\
\hline $\begin{array}{l}\text { Heterogeneity: } \tau^{2} \\
\text { Test for overall eff }\end{array}$ & $\begin{array}{l}0.20 ; \chi^{2}= \\
\text { ct: } Z=0.3\end{array}$ & $\begin{array}{l}4.76, \text { d.f. }=2 \\
4(p=0.73)\end{array}$ & $\mathrm{b}=0.09)$ & ${ }^{2}=58 \%$ & & & $\begin{array}{r}0.01 \\
\text { ex }\end{array}$ & $\begin{array}{c}0.1 \\
\text { Favors } \\
\text { experimental }\end{array}$ & $\begin{array}{c}10 \\
\text { Favors } \\
\text { control }\end{array}$ & 100 \\
\hline
\end{tabular}

Fig. 4. Forest plot: bleeding complications after preoperative AP withdrawal versus continuing AP in PPB. 


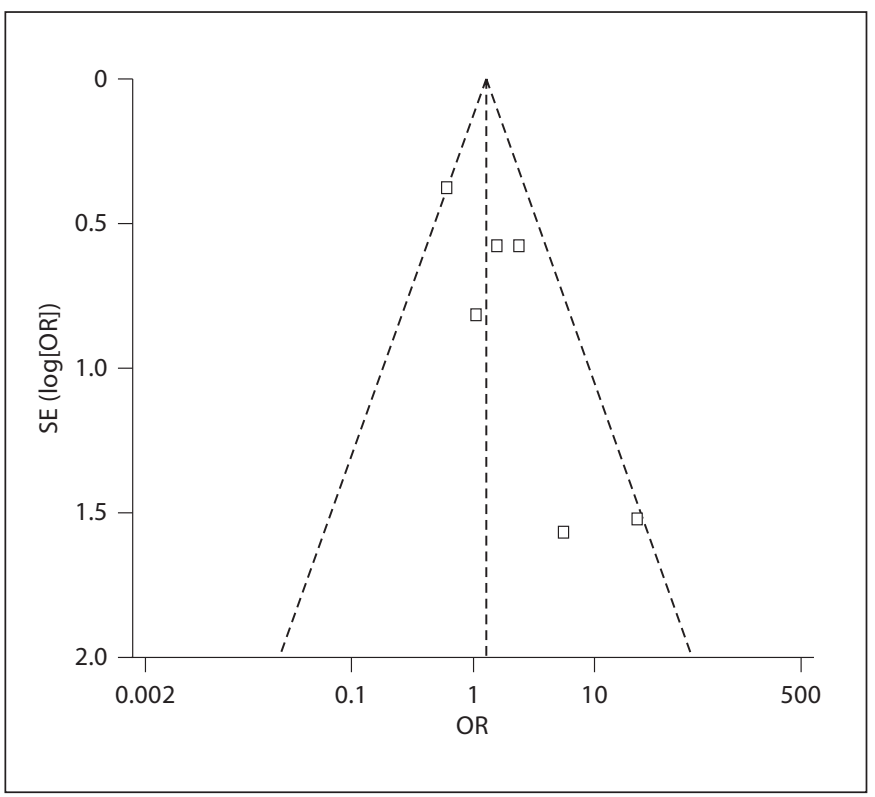

Fig. 5. Funnel plot: bleeding complications after preoperative AP withdrawal versus continuing AP during TURP.

moproctia and hemospermia. The data collected was heterogeneous ( $\left.\mathrm{p}=0.09, \mathrm{I}^{2}=58 \%\right)$ and we therefore used the random-effects model. The results revealed that the difference of bleeding complications for PPB was not statistically significant (OR 0.89, 95\% CI 0.45-1.76, $\mathrm{p}=0.73$ ).

Funnel Plot Analysis

The funnel plot indicated that studies which may have demonstrated increased OR with low precision may not have been published (fig. 5, 6).

\section{Fall-Safe Numbers}

The funnel plot showed evidence of publication bias. We calculated the fall-safe numbers (Nfs) to help identify publication bias by Rosenthal's method [12], which calculates the number of additional studies, meaning the number of studies that would need to be added to a meta-analysis to reduce the statistically significant observed result to non-significance. The p value was usually 0.05 or 0.01 . $\mathrm{Nfs}$ is calculated as

$$
\mathrm{Nfs}=\left(\Sigma \mathrm{Z}\left(p_{\mathrm{i}}\right) / \mathrm{Z} p\right)^{2}-\mathrm{n},
$$

where $\mathrm{n}$ is the number of studies, $\mathrm{Z}\left(p_{\mathrm{i}}\right)$ are the $\mathrm{Z}$-scores for the individual significance values, and $Z p$ is the onetailed Z-score associated with the desired $p$. The Nfs were 18 and 7 for TURP when $p$ values were 0.05 and 0.01 re-

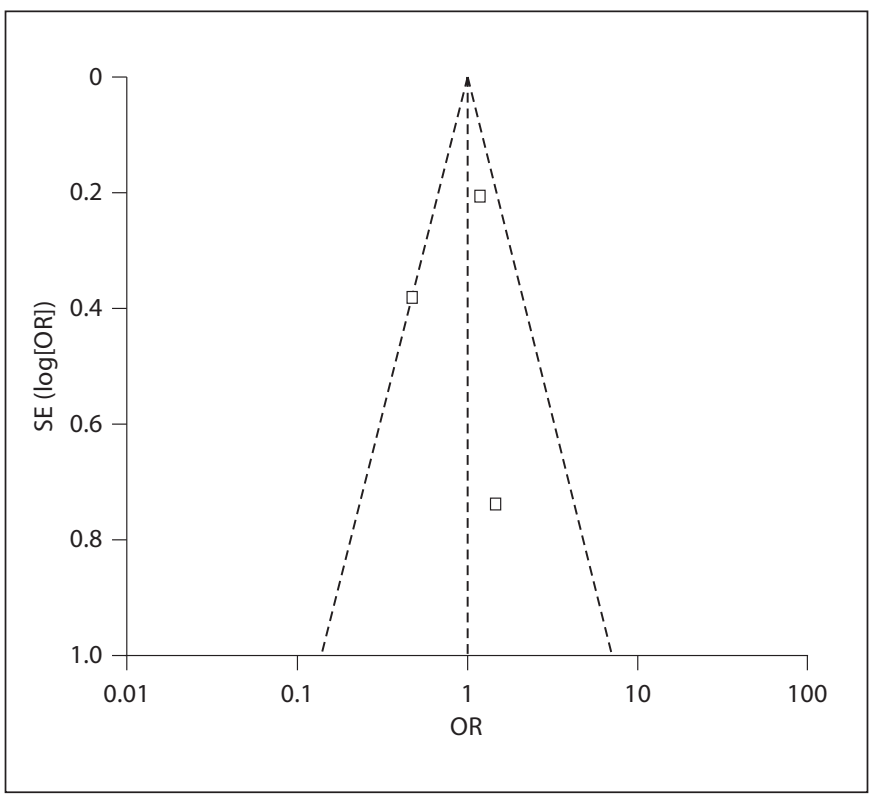

Fig. 6. Funnel plot: bleeding complications after preoperative AP withdrawal versus continuing AP in $\mathrm{PPB}$.

spectively. The large number of Nfs are relative to low publication bias.

It was not necessary to calculate the Nfs for the small amount of literature included in our study about PPB. We found asymmetry using the funnel plot which indicated publication bias.

\section{Discussion}

With the development of intraoperative artificial material insertion and the aging population, more patients will ingest APs such as aspirin in the long term. However, there is research reporting that preoperative AP therapy significantly increases the risk of bleeding, such as orthopedic surgery $[15,16]$, cardiosurgery [17] and tonsillectomy [17]. In a prospective cohort study of 202 patients undergoing elective coronary artery bypass grafting, Taggart et al. [18] reported that low-dose aspirin therapy could significantly increase postoperative hemorrhage, resulting in the increase of blood transfusions and hemostatic requirements, but without prolonging postoperative hospital stay.

In 1993, Thurston and Briant [13] documented 2 patients who had severe hemorrhage following TURP, suggesting that attention should be paid before surgery in patients taking APs, like aspirin. Ala-Opas and Gronlund 
[5] investigated the blood loss in 42 long-term aspirin users undergoing TURP versus 40 men in a control group, and suggested that aspirin did not increase blood loss during TURP. A large-scale retrospective examination of 457 patients undergoing TURP recommended withdrawal of acetylsalicylic acid and non-steroidal anti-inflammatory drugs 1 week before TURP to reduce the risk of bleeding [6]. Kearon and Hirsh [19] considered that the increasing incidence of thrombus complications resulted from stopping APs. In the literature, including this study, there are no reports about cardiocerebrovascular incidents after stopping using APs. Our study analyzed 9 published trials and compared preoperative AP withdrawal with continuing AP in urological surgery. The results revealed that no differences were found in risk of bleeding after TURP and PPB.

Our study has a number of limitations which may lead to bias: (1) Only two randomized controlled trials in the literature were included, the rest were retrospective clinical controlled trials of low quality. This may affect the reliability of the results due to the lack of not being multi-center, large-sample and high-quality research trials. (2) Only one study in the literature reported the withdrawal time to be 1 week [7], the rest referred to with- drawal times of 5-10 days and lower doses without detailed descriptions. This may also affect postoperative blood complications. (3) The lack of non-significant, unpublished or missing studies may result in publication bias and affect the meta-analysis result. Some clinical research about other APs has not been included in our study. Further clinical research is warranted to re-examine this issue and permit the development of evidencebased guidelines to manage the antiplatelet patient requiring TURP and PPB.

\section{Conclusion}

In our study, continuing APs do not increase the risk of postoperative bleeding compared with stopping APs before TURP and PPB. We consider that patients with APs can also receive TURP and PPB without discontinuing APs. When the present research results are chosen as a reference by urological surgeons, it is necessary to make reasonable adjustment for other research results, clinical experience and the individual patient characteristics in clinical practice.

\section{References}

1 Burger W, Chemnitius JM, Kneissl GD, Rucker G: Low-dose aspirin for secondary cardiovascular prevention: cardiovascular risks after its perioperation withdrawal versus bleeding risks with its continuation: review and meta-analysis. J Intern Med 2005; 257:399-414.

2 Kretschmer V: Perioperative risk of hemorrhage in urologic operations caused by administration of aspirin. Urologe A 1998;37: 675.

-3 Jadad AR, Moore RA, Carroll D, Jenkinson C, Reynolds DM, Gavaghan DJ, McQuay HJ: Assessing the quality of reports of randomized clinical trials: is blinding necessary? Control Clin Trials 1996;17:1-12.

4 Liu J: Systematic review of nonrandomized controlled trials. Chin J Evid Based Med 2001;1:239-243.

5 Ala-Opas MY, Gronlund SS: Blood loss in long-term aspirin users undergoing transurethral prostatectomy. Scand J Urol Nephrol 1996;30:203-206.

-6 Wierød FS, Frandsen NJ, Jacobsen JD, Hartvigsen $A$, Olsen PR: Risk of haemorrhage from transurethral prostatectomy in acetylsalicylic acid and NSAID-treated patients. Scand J Urol Nephrol 1998;32:120-122.
7 Giannarin G, Mogorovich A, Valent F, Morelli G, De Maria M, Manassero F, Barbione F, Selli C: Continuing or discontinuing lowdose aspirin before transrectal prostate puncture biopsy: results of a prospective randomized trial. Urology 2007;70:501-505.

$\checkmark 8$ Herget EJ, Saliken JC, Donnelly BJ, Gray RR, Wiseman D, Brunet G: Transrectal ultrasound-guided biopsy of the prostate: relation between aspirin use and bleeding complications. Can Assoc Radiol J 1999;50:173176.

$>9$ Kariotis I, Philippou P, Volanis D, Serafetinides E, Delakas D: Safety of ultrasound-guided transrectal extended prostate puncture biopsy in patents receiving lowdose aspirin. Int Braz J Urol 2010;36:308-316.

$>10$ Maan Z, Cutting CW, Patel U, Kerry S, Pietrzak P, Perry MJA, Kirby RS: Morbidity of transrectal ultrasonography-guided prostate biopsies in patients after the continued use of low-dose aspirin. BJU Int 2003;91: 798-800.

11 Nielsen JD, Holm-Nielsen A, Jespersen J, Vinther CC, Settgast IW, Gram J: The effect of low-dose acetylsalicylic acid on bleeding after transurethral prostatectomy - a prospective, randomized, double-blind, placebo-controlled study. Scand J Urol Nephrol 2000;34:194-198.
12 Rosenthal R: The 'file drawer problem' and tolerance for null results. Psychol Bull 1979; 86:638-641.

13 Thurston AV, Briant SL: Aspirin and postprostatectomy haemorrhage. Br J Urol 1993; 71:574-576.

14 Watson CJ, Deane AM, Doyle PT, Bullock $\mathrm{KN}$ : Identifiable factors in post-prostatectomy haemorrhage: the role of aspirin. $\mathrm{Br} \mathrm{J}$ Urol 1990;66:85-87.

15 Freiberg A, Cantor R, Freiberg R: The use of aspirin to prevent heterotopic ossification after total hip arthroplasty. Clin Orthop 1991;267:93-96.

16 Schmidt S, Andersen P, Pedersen NW, Kristensen SS, Pedersen P, Nielsen JB: The use of indomethacin to prevent the formation of heterotopic bone after total hip replacement. J Bone Joint Surg Am 1988;70:834-838.

17 Stage J, Jensen J, Bonding P: Post-tonsillectomy haemorrhage and analgesics. A comparative study of acetylsalicylic acid and paracetamol. Clin Otolaryngol 1988;13:201-204.

18 Taggart D, Siddiqui A, Wheatley D: Lowdose preoperative aspirin therapy, postoperative blood loss and transfusion requirements. Thorac Surg 1990;50:425-428.

19 Kearon C, Hirsh J: Management of anticoagulation before and after elective surgery. N Engl J Med 1997;336:1506-1511. 